\title{
Impact factors: a tool of the sterile audit culture
}

\author{
Stalked by accountants, unaware of pre-Internet work, how can young scientists thrive?
}

Sir - I have added Peter A. Lawrence's

Commentary on "The politics of publication" (Nature 422, 259-261; 2003) and David Colquhoun's incisive Correspondence response "Challenging the tyranny of impact factors" (Nature $423,479 ; 2003)$ to a very small collection of items on this subject which are de rigueur reading for everyone in my group, no matter how senior or copiously cited. The two others are "Is science losing its objectivity?” (J. Ziman, Nature 382, 751-754; 1996) and "The martial art of scientific publication” (E. N. Parker, Eos 78, 393-395; 1997).

Asking the young scientists for whom I have responsibility to read these articles is the best way I can think of to meet Lawrence's question of what we can do about the situation that he so clearly diagnosed. The audit culture and the bragging attitude it sustains are advancing on all fronts; accountants and administrators armed with networked computers are the downside of the advances that have transformed the way in which we are able to analyse scientific data. There seems to be no appreciation of the once unchallenged argument that the scientific goose that lays the golden eggs needs some tall green grass, privacy and free choice of nesting sites. It does not respond well to weekly or quarterly requests for deliverables and activity reports.

I fear that electronic publishing, while conferring obvious benefits such as connectivity and searchability of the literature, may exacerbate the situation. I have had a paper to review which cited about 30 references, hardly any of them more than 10 years old. When I commented that this was unfair to earlier workers, I received the response that older references were not available on the e-accessible database at the author's institution!

This anecdote typifies a detectable trend and, I believe, is one that risks causing serious erosion of the knowledge base - not to mention the fact that the pioneers in a subject often stated the principles and problems with far greater clarity than many modern authors do.

One suggestion would be for a team of senior scientists, or perhaps national academies around the globe, to produce a handbook on responsibilities, rights and privileges as regards publication. It would be for all scientists but specifically aimed at entrants to the research enterprise. Even if one could not get agreement from those who successfully operate the present system to their advantage, at least the debate, if public, would raise consciousness.

Adrian Tuck

National Oceanic and Atmospheric

Administration Aeronomy Laboratory R/AL6,

325 Broadway, Boulder,

Colorado 80305-3328, USA

\section{Reproductive cloning: don't rush to judgement}

Sir - Your News story "Researchers divided over ethics of a ban on cloning" (Nature 423, 373; 2003), describing the possible lack of ethical grounds for banning safe reproductive cloning, shows the perils of legislating early in the developmental trajectory of a technology. If human reproductive cloning becomes safe, protecting the welfare of cloned persons - who will be as unique and worthy of respect as any other person will cease to be a strong reason to oppose reproductive cloning.

A more fruitful policy approach would then be to ask whether safe cloning would serve important reproductive or familial needs, and if so, what the impact of allowing cloning in those cases would be. An important distinction in this regard is between cloning to establish a family connection, as might occur in the case of severe gametic infertility, and cloning by fertile persons to choose the genotype of a child. Cloning when infertile to have an otherwise unavailable genetic connection with a child serves a different need and is arguably more deserving of societal respect than cloning by a fertile couple to choose a particular genome.

Whether legal bans are needed if cloning is safe should depend upon a much finer-grained policy analysis than has occurred in the current rush to prohibit all cloning. If safe uses of cloning are not feasible, few responsible practitioners will offer the procedure. Even if cloning can be made safe, few otherwise fertile persons are likely to seek it or have a legitimate claim for it.

Legislating now to ban all cloning carries a high price, both in limiting potential future legitimate uses and in preventing researchers from cloning embryos for stem-cell or genetic-disease research. The possible dangers involved in reproductive cloning are too vague and unrealized to drive national and international policy covering all forms of cloning.

\section{John A. Robertson}

University of Texas School of Law, 727 East Dean Keeton Street, Austin, Texas 78705, USA

\section{Reproductive cloning: an attack on human dignity}

Sir - In your News story "Researchers divided over ethics of a ban on cloning" (Nature 423, 373; 2003), about the German government's proposed ban on all types of human cloning, you report that some bioethicists regard the main argument against human cloning to be the risk of spontaneous abortion or ill-health in the offspring. Hence they argue that, if these risks were overcome, other arguments against human cloning would not withstand ethical analysis.

However, I suspect that most people do not delegate their moral or ethical judgements to professional ethicists, but make judgements themselves on the basis of their personal philosophy (which may or may not have a religious underpinning) or of the 'gut feeling' that results from this.

I personally am completely opposed to human cloning of any sort, from a feeling of utter repugnance towards what appears to me to be a fundamental assault on human dignity, with the potential for horrendous misuse.

If this is a minority opinion among biological scientists, I suspect that it has a wider resonance among the general public, especially in countries with memories of the infamies perpetrated in the name of science and medicine.

I, like many scientists, am an atheist, but I do not think that anyone has a licence to play God.

\section{David P. Leader}

Institute of Biomedical and Life Sciences,

University of Glasgow,

Glasgow G12 8QQ, UK

\section{correspondence}

Contributions to Correspondence may be submitted to corres@nature.com. They should be no longer than 500 words, and ideally shorter. Published contributions are edited. 